\title{
Synthesis of Mesoporous Silica Nanofibers with Defined Pore Architectures
}

\author{
Jianfang Wang, Chia-Kuang Tsung, Wenbin Hong, Yiying Wu, Jing Tang, Galen D. Stucky \\ Mitsubishi Chemical Center for Advanced Materials, Department of Chemistry and Biochemistry, and \\ Materials Department, University of California, Santa Barbara, California 93106
}

\section{Supporting Information}

\section{Characterization}

Low-angle XRD patterns in $2 \theta$ ranges of $0.5-6^{\circ}$ with a step of $0.02^{\circ}$ and time per step of $2 \mathrm{~s}$ were

obtained on a Scintag PADX diffractometer using $\mathrm{Cu} \mathrm{K}_{\alpha}$ radiation and allowing for the measurement of $2 \theta$ angles down to $0.5^{\circ}$. SEM studies were performed on a JEOL $6340 \mathrm{~F}$ microscope operating at $2-5$ $\mathrm{keV}$. TEM studies were carried out on a JEOL 2010 microscope operating at $200 \mathrm{keV}$. Reaction products were dispersed into ethanol and then deposited onto silicon wafers and copper grids coated with carbon-stabilized lacey formvar for SEM and TEM imaging, respectively. High-resolution TEM images were obtained with a Gatan charge coupled device (CCD) connected to the microscope. In order to be able to observe the pore channel arrangement with the viewing direction parallel to the fiber axis, nanofiber samples were embedded into a thermo-curable resin (Eponate 12 kit, Ted Pella, catalog number: 18010) and kept at $60{ }^{\circ} \mathrm{C}$ overnight. The embedded nanofiber samples were then microtomed into thin slices of $\sim 70 \mathrm{~nm}$ thickness, which were transferred onto bare copper grids for TEM observations. Nitrogen adsorption and desorption isotherms were measured using a Micromeritics TriStar 3000 system at $77 \mathrm{~K}$ after the samples were degassed with flowing nitrogen at $200{ }^{\circ} \mathrm{C}$ overnight. The sorption data were analyzed using the BJH model with Halsey equation for multilayer thickness. The pore size distribution was obtained from the analysis of the adsorption branch. The pore volume was taken at the single point at a relative pressure of 0.99. A Netzsch thermoanalyzer STA 409 was used for recording TGA and DTA traces simultaneously with a heating rate of $5{ }^{\circ} \mathrm{C} / \mathrm{min}$ in air. A Nikon optical microscope was used to obtain fluorescence images and spectra of mesostructured nanofibers doped with Rh6G. Nanofibers were excited with the $488 \mathrm{~nm}$ line from a Spectra-Physics 2065 argon ion 
laser. A long-pass filter (OG515, Melles Griot) was used to remove excitation light. Fluorescence images were taken using a Sony DXC-970MD color video camera coupled with the optical microscope.

For fluorescence spectra, light emerging from individual nanofibers was selected by a pinhole and guided with an optical fiber to the entrance slit of a spectrometer (150 groves $/ \mathrm{mm})$ equipped with a liquid nitrogen cooled back-illuminated CCD.

\section{Tables}

Table S1. $d$ Spacings and Lattice Constants, $a$, determined from the Low-Angle XRD Patterns of Mesoporous Nanofiber Samples ${ }^{\mathrm{a}}$

\begin{tabular}{cccccc}
\hline Sample & $\begin{array}{c}d(100) \\
(\mathrm{nm})\end{array}$ & $\begin{array}{c}d(110) \\
(\mathrm{nm})\end{array}$ & $\begin{array}{c}d(200) \\
(\mathrm{nm})\end{array}$ & $\begin{array}{c}d(210) \\
(\mathrm{nm})\end{array}$ & $a(\mathrm{~nm})$ \\
\hline $\mathrm{A}$ & 4.09 & 2.36 & 2.05 & & 4.72 \\
$\mathrm{~B}$ & 3.82 & 2.19 & 1.91 & & 4.40 \\
$\mathrm{C}$ & 4.09 & 2.37 & 2.05 & & 4.73 \\
$\mathrm{D}$ & 3.69 & 2.16 & 1.88 & & 4.31 \\
$\mathrm{E}$ & 4.54 & 2.62 & 2.29 & 1.73 & 5.27 \\
$\mathrm{~F}$ & 4.58 & 2.53 & 2.22 & 1.66 & 5.14
\end{tabular}

${ }^{a} \mathrm{~A}$ : nanofibers grown with $\mathrm{C}_{16} \mathrm{TMAC}$ at $50{ }^{\circ} \mathrm{C}$ before calcination. $\mathrm{B}$ : nanofibers grown with $\mathrm{C}_{16} \mathrm{TMAC}$ at $50{ }^{\circ} \mathrm{C}$ after calcination. C: nanofibers grown with $\mathrm{C}_{16} \mathrm{TMAC}$ at $85^{\circ} \mathrm{C}$ before calcination. D: nanofibers grown with $\mathrm{C}_{16} \mathrm{TMAC}$ at $85{ }^{\circ} \mathrm{C}$ after calcination. $\mathrm{E}$ : nanofibers grown with $\mathrm{C}_{18} \mathrm{TMAB}$ at 70 ${ }^{\circ} \mathrm{C}$ before calcination. F: nanofibers grown with $\mathrm{C}_{18} \mathrm{TMAB}$ at $70{ }^{\circ} \mathrm{C}$ after calcination.

Table S2. $d$ Spacings and Lattice Constants, $a$, determined from the Low-Angle XRD Patterns of Mesoporous Curve-Shaped Particles ${ }^{\mathrm{a}}$

\begin{tabular}{ccccc}
\hline Sample & $\begin{array}{c}d(100) \\
(\mathrm{nm})\end{array}$ & $\begin{array}{c}d(110) \\
(\mathrm{nm})\end{array}$ & $\begin{array}{c}d(200) \\
(\mathrm{nm})\end{array}$ & $a(\mathrm{~nm})$ \\
\hline $\mathrm{A}$ & 3.66 & 2.18 & 1.89 & 4.32 \\
$\mathrm{~B}$ & 3.56 & 2.10 & 1.86 & 4.20 \\
$\mathrm{C}$ & 3.95 & 2.29 & 2.01 & 4.59 \\
$\mathrm{D}$ & 3.76 & 2.20 & 1.92 & 4.39
\end{tabular}


${ }^{\mathrm{a}} \mathrm{A}$ : particles grown with $\mathrm{C}_{16} \mathrm{TMAC}$ at $50{ }^{\circ} \mathrm{C}$ before calcination. $\mathrm{B}$ : particles grown with $\mathrm{C}_{16} \mathrm{TMAC}$ at $50{ }^{\circ} \mathrm{C}$ after calcination. C: particles grown with $\mathrm{C}_{16} \mathrm{TMAC}$ at $85{ }^{\circ} \mathrm{C}$ before calcination. D: particles grown with $\mathrm{C}_{16} \mathrm{TMAC}$ at $85^{\circ} \mathrm{C}$ after calcination.

Table S3. Pore Characteristics of Curve-Shaped Mesoporous Particles ${ }^{\mathrm{a}}$

\begin{tabular}{ccccc}
\hline Sample & $\begin{array}{c}S_{B E T} \\
\left(\mathrm{~m}^{2} / \mathrm{g}\right)\end{array}$ & $\begin{array}{c}\left.\mathrm{c}_{B J H} / \mathrm{g}\right) \\
(\mathrm{nm})\end{array}$ & $\begin{array}{c}\text { FWHM } \\
(\mathrm{nm})\end{array}$ \\
\hline A & 1100 & 0.76 & 2.7 & 0.6 \\
B & 1100 & 1.05 & 2.7 & 0.9
\end{tabular}

${ }^{\mathrm{a}} \mathrm{A}$ : particles grown with $\mathrm{C}_{16} \mathrm{TMAC}$ at $50{ }^{\circ} \mathrm{C}$. B: particles grown with $\mathrm{C}_{16} \mathrm{TMAC}$ at $85{ }^{\circ} \mathrm{C}$.

\section{Figures}

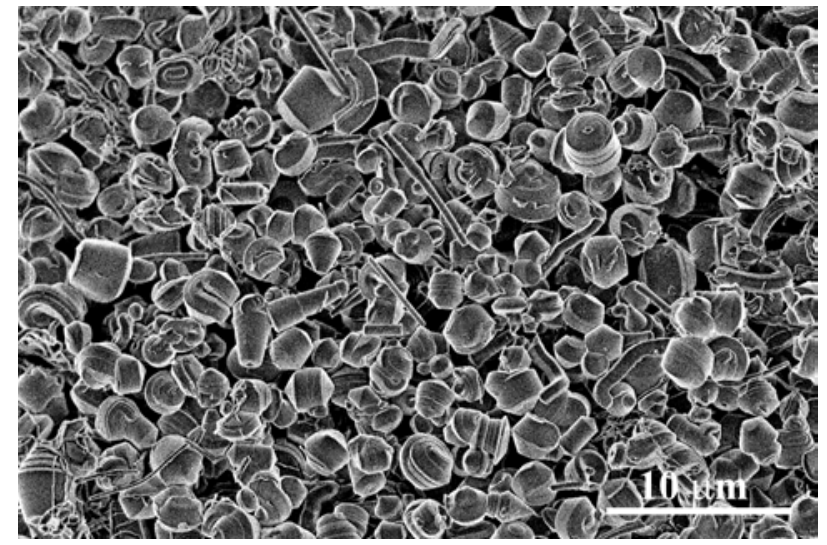

Figure S1. SEM image of the particles

synthesized with $\mathrm{C}_{16}$ TMAC surfactant at 50

${ }^{\circ} \mathrm{C}$.
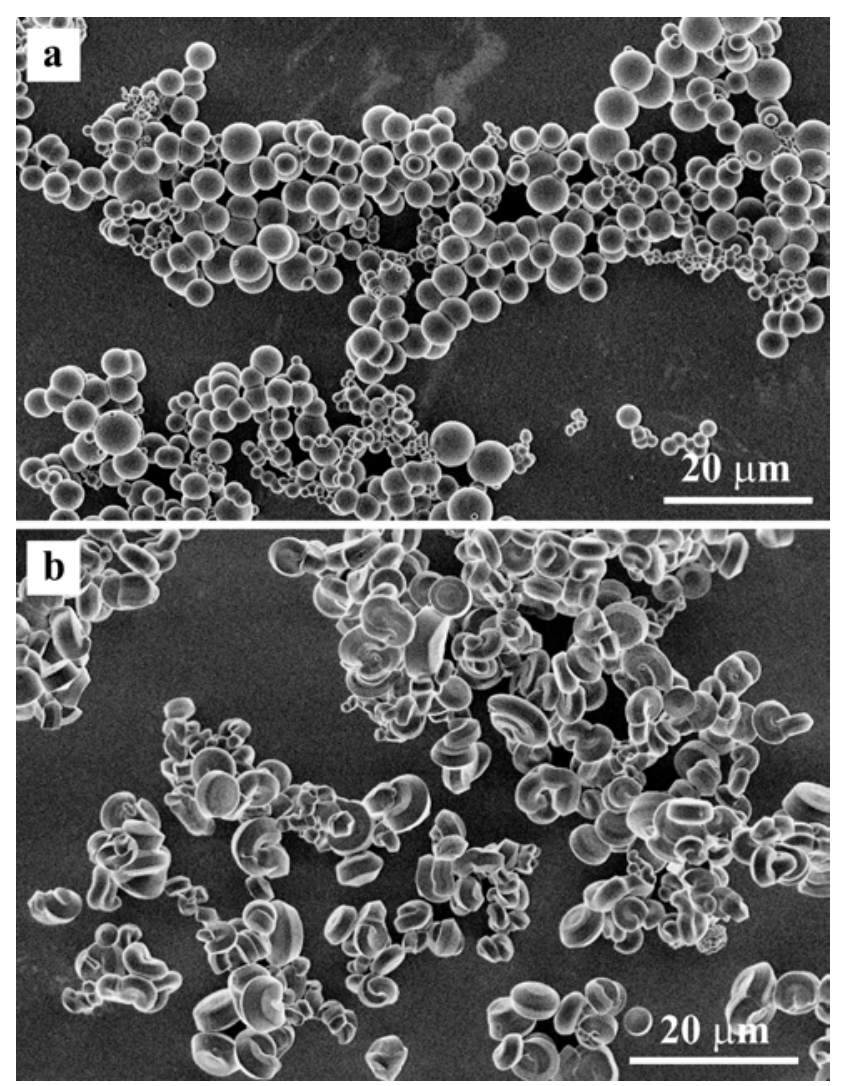

Figure S2. SEM images of the products synthesized with (a) $\mathrm{C}_{12} \mathrm{TMAB}$ and (b) $\mathrm{C}_{14} \mathrm{TMAB}$ surfactants at $60{ }^{\circ} \mathrm{C}$. 


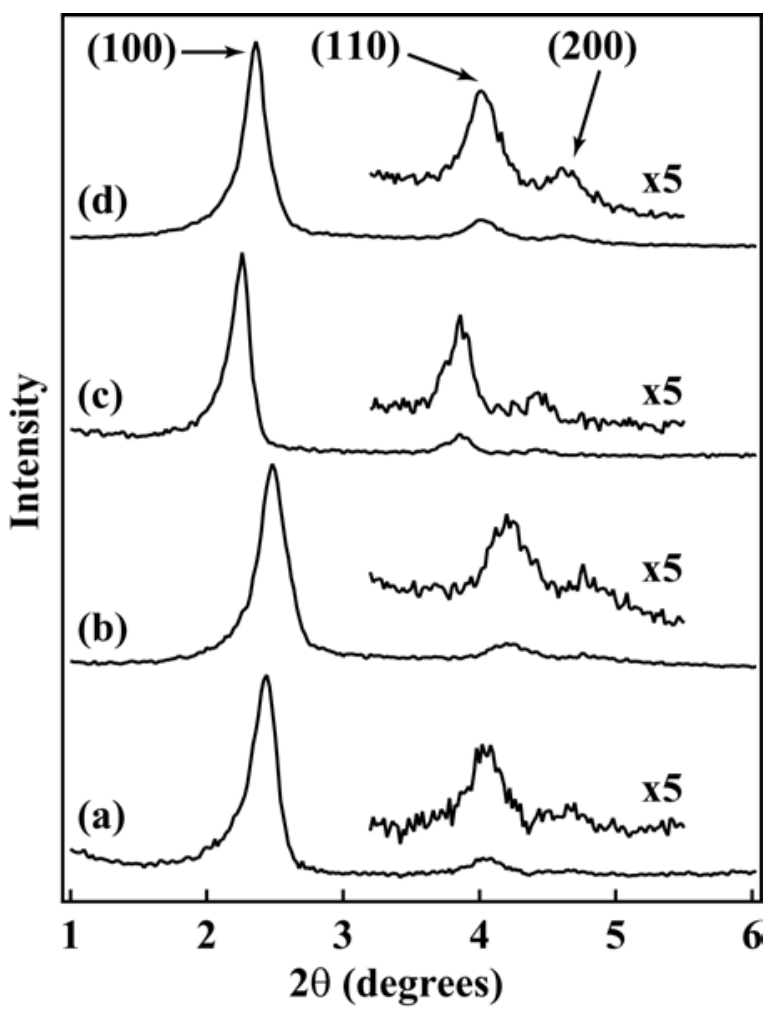

Figure S3. Low-angle XRD patterns of mesoporous curve-shaped particles synthesized with $\mathrm{C}_{16}$ TMAC surfactant. (a) and (b) Particles grown at $50{ }^{\circ} \mathrm{C}$ before and after calcination. (c) and (d) Particles grown at $85^{\circ} \mathrm{C}$ before and after calcination.

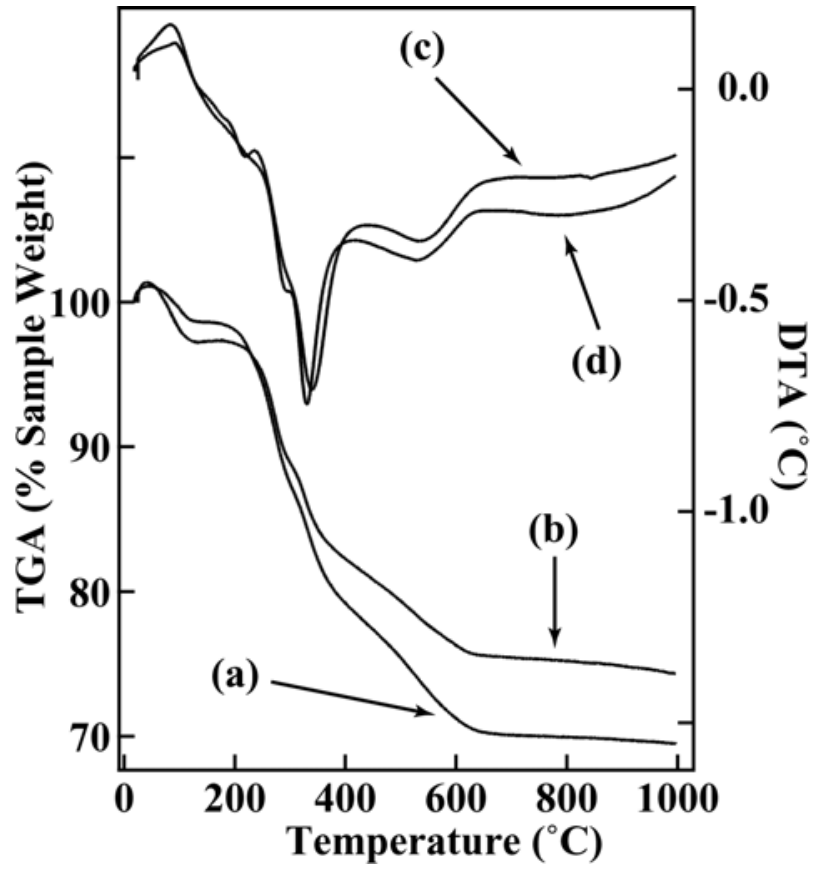

Figure S4. TGA and DTA traces recorded on the nanofiber samples synthesized with $\mathrm{C}_{16}$ TMAC surfactant. (a) and (c) are TGA and DTA traces for the sample grown at 50 ${ }^{\circ} \mathrm{C}$, respectively. (b) and (d) are TGA and DTA traces for the sample grown at $85^{\circ} \mathrm{C}$, respectively. The total weight losses for the nanofibers grown at $50^{\circ} \mathrm{C}$ and $85^{\circ} \mathrm{C}$ are 30 wt $\%$ and $25 \mathrm{wt} \%$, respectively. The sharp exothermic peaks due to the combustion and decomposition of organic surfactants in air for the nanofibers grown at $50{ }^{\circ} \mathrm{C}$ and $85{ }^{\circ} \mathrm{C}$ are at $340{ }^{\circ} \mathrm{C}$ and $330{ }^{\circ} \mathrm{C}$, respectively. 


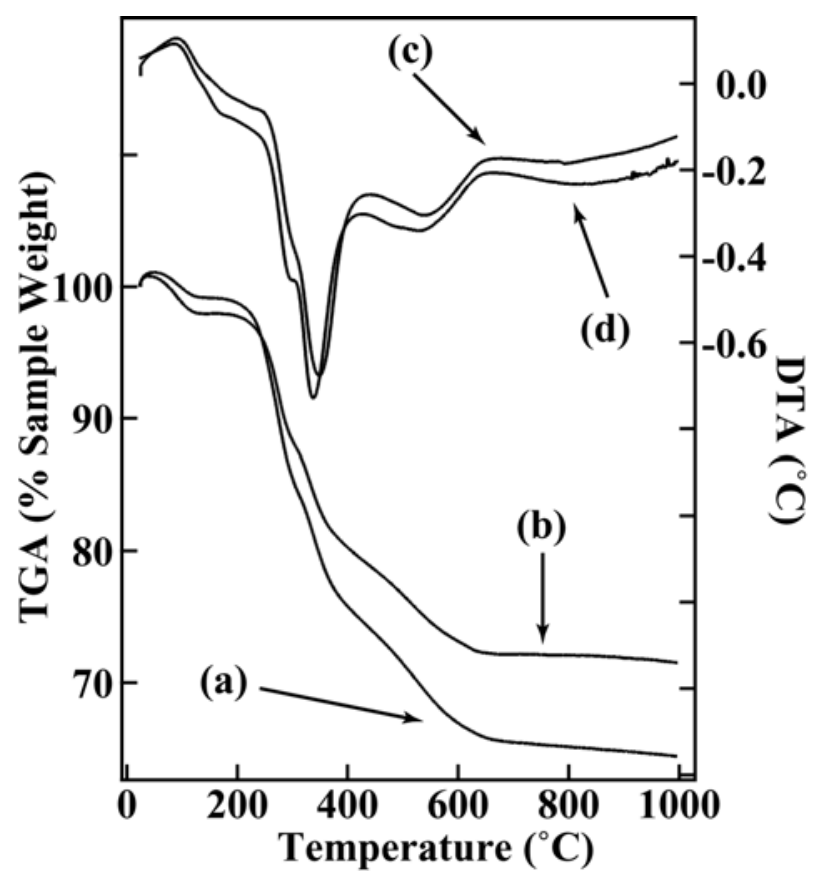

Figure S5. TGA and DTA traces recorded on the curve-shaped particle samples synthesized with $\mathrm{C}_{16}$ TMAC surfactant. (a) and (c) are TGA and DTA traces for the particle sample grown at $50^{\circ} \mathrm{C}$, respectively. (b) and (d) are TGA and DTA traces for the particle sample grown at $85^{\circ} \mathrm{C}$, respectively. The total weight losses for the particles grown at $50{ }^{\circ} \mathrm{C}$ and $85{ }^{\circ} \mathrm{C}$ are $35 \mathrm{wt} \%$ and $28 \mathrm{wt} \%$, respectively. The sharp exothermic peaks due to the combustion and decomposition of organic surfactants in air for the particles grown at $50^{\circ} \mathrm{C}$ and $85^{\circ} \mathrm{C}$ are at $349^{\circ} \mathrm{C}$ and $338^{\circ} \mathrm{C}$, respectively.

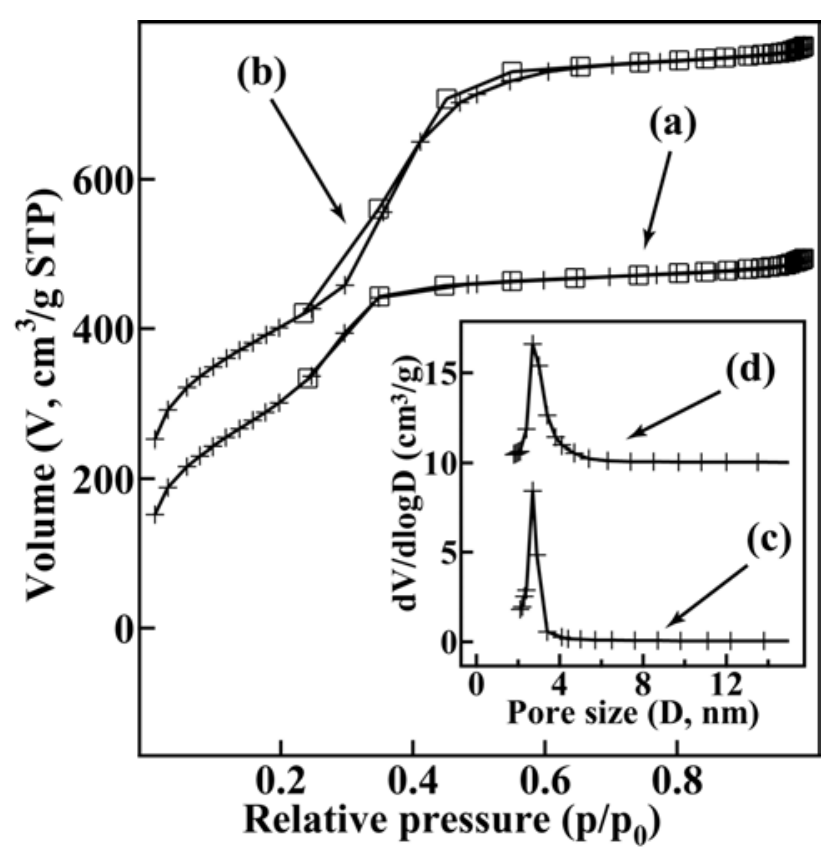

Figure S6. Nitrogen sorption isotherms of curve-shaped particles. (a) Particles synthesized with $\mathrm{C}_{16}$ TMAC surfactant at 50 ${ }^{\circ} \mathrm{C}$. (b) Particles synthesized with $\mathrm{C}_{16} \mathrm{TMAC}$ surfactant at $85^{\circ} \mathrm{C}$. Crosses represent the adsorption branches, and squares represent the desorption branches. The isotherm (b) has been shifted up $100 \mathrm{~cm}^{3} / \mathrm{g}$. (c) and (d) in the inset show BJH pore-size distributions obtained from the adsorption branches of (a) and (b), respectively. The pore-size distribution (d) has been shifted up $10 \mathrm{~cm}^{3} / \mathrm{g}$. 

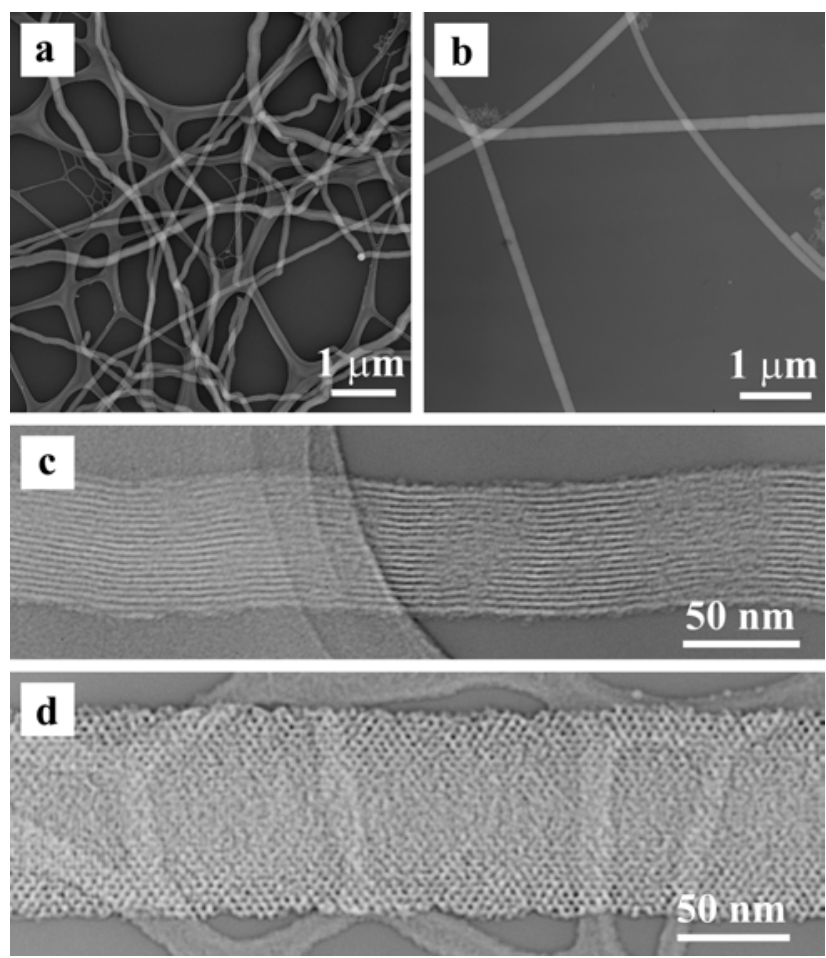

Figure S7. (a) Low-magnification TEM image of the nanofibers synthesized with $\mathrm{C}_{16}$ TMAC surfactant first at $50{ }^{\circ} \mathrm{C}$ for $14 \mathrm{hrs}$ and then at $85^{\circ} \mathrm{C}$ for $48 \mathrm{hrs}$. (b) Lowmagnification TEM image of the nanofibers synthesized with $\mathrm{C}_{16}$ TMAC surfactant first at $85^{\circ} \mathrm{C}$ for $24 \mathrm{hrs}$ and then at $50^{\circ} \mathrm{C}$ for $48 \mathrm{hrs}$. (c) High-magnification TEM image of one nanofiber synthesized as in (a). (d) Highmagnification TEM image of one nanofiber synthesized as in (b). 